\title{
Metabolism of glycerol by mature boar spermatozoa
}

\author{
A. R. Jones, L. A. Chantrill and A. Cokinakis \\ Department of Biochemistry, The University of Sydney, Sydney NSW 2006, Australia
}

\begin{abstract}
Summary. Mature boar spermatozoa oxidized glycerol to carbon dioxide in the absence of any detectable activity of glycerol kinase. With triosephosphate isomerase and glyceraldehyde-3-phosphate dehydrogenase inhibited by the presence of 3-chloro-1hydroxypropanone (CHOP), dihydroxyacetone phosphate accumulated in incubates when glycerol-3-phosphate was the substrate, but not when it was glycerol. Both dihydroxyacetone and glyceraldehyde could be used as substrates; in the presence of CHOP, dihydroxyacetone phosphate and fructose-1,6-bisphosphate accumulated when dihydroxyacetone was the substrate, but not when it was glyceraldehyde. The metabolic pathways glycerol $\rightarrow$ glyceraldehyde $\rightarrow$ glyceraldehyde 3-phosphate and dihydroxyacetone $\rightarrow$ dihydroxyacetone phosphate have been shown to operate in these cells.
\end{abstract}

Ke. wrords: glycerol; glycerol kinase; glyceraldehyde; dihydroxyacetone; spermatozoa; boar

\section{Introduction}

The ability of spermatozoa of a number of species to utilize glycerol has been well established. Glycerol stimulates oxygen consumption by ram (Mann \& White, 1956, 1957), bull (White, 1957), boar (Aalbers et al., 1961) and goat spermatozoa (Mohri et al., 1970) and $\left[{ }^{14} \mathrm{C}\right]$ glycerol is oxidized to ${ }^{14} \mathrm{CO}_{2}$ by rat (Cooper \& Brooks, 1981) and human spermatozoa (Murdoch \& White, 1968). We have confirmed that mature boar spermatozoa oxidize glycerol to $\mathrm{CO}_{2}$ (Jones \& Chantrill, 1989), but the mechanism has not been established. The 'classical' pathway of glycerol metabolism is its conversion to glycerol-3-phosphate, which is oxidized to dihydroxyacetone phosphate, an intermediate of the glycolytic pathway (Stryer, 1988). The production of glycerol-3-phosphate requires ATP and glycerol kinase (EC 2.7.1.30), but the activity of this enzyme is not detectable in the spermatozoa of several species, including man, and is reported to have low activity in the spermatozoa of others, including boar (Mohri \& Masaki, 1967).

We present the results of a comparative study of the metabolism of glycerol, glycerol-3phosphate, glyceraldehyde and dihydroxyacetone in mature boar spermatozoa. Use has been made of 3-chloro-1-hydroxypropanone (CHOP), which is converted by triosephosphate isomerase into (S)-3-chlorolactaldehyde (Stevenson \& Jones, 1985), a specific inhibitor of sperm triosephosphate isomerase (EC 5.3.1.1) and glyceraldehyde 3-phosphate dehydrogenase (EC 1.2.1.12) (Jones \& Cooney, 1987; Cooney \& Jones, 1988).

\section{Materials and Methods}

Chemicals and substrates. 3-Chloro-1-hydroxypropanone (CHOP) was prepared to established purity by the procedure of Jones et al. $(1986) .\left[\mathrm{U}-{ }^{14} \mathrm{C}\right] \mathrm{Glycerol},\left[2-{ }^{14} \mathrm{C}\right] \mathrm{glycerol},\left[1,3-{ }^{14} \mathrm{C}\right]$ glycerol and $\mathrm{L}-\left[\mathrm{U}-{ }^{14} \mathrm{C}\right] \mathrm{glycerol}-3$-phosphate were purchased from Amersham International plc (Amersham, HP7 9LL, UK). All enzymes, substrates and cofactors were obtained from Sigma Chemical Co. (St Louis, MO 63178, USA) or Boehringer Mannheim Australia Pty Ltd (North Ryde, NSW 2113, Australia). Dihydroxyacetone was from Sigma Chemical Co and D,L-glyceraldehyde from BDH Chemicals Ltd (Poole, Dorset BHI2 4NN, UK). All other chemicals and reagents were of analytical grade and all solutions were prepared in water purified by reverse osmosis. 
Metabolic studies. The collection of mature boar spermatozoa, the preparation of washed suspensions of cells, the incubation parameters and the processing of incubates have been previously described (Jones \& Chantrill, 1989). All incubations were performed with substrate concentrations at $2 \mathrm{mmol} / \mathrm{l}$ except for $\mathrm{D}, \mathrm{L}-\mathrm{glyceraldehyde}$, which was used at $4 \mathrm{mmol} / 1$ ( $\equiv 2 \mathrm{mmol} \mathrm{D-glyceraldehyde/1).} \mathrm{When} \mathrm{CHOP} \mathrm{was} \mathrm{used} \mathrm{as} \mathrm{a} \mathrm{metabolic} \mathrm{inhibitor,} \mathrm{it} \mathrm{was} \mathrm{present} \mathrm{in}$ incubates at either 0.5 or $1 \mathrm{mmol} / \mathrm{l}$. Assays for metabolically derived $\mathrm{CO}_{2}$ (Stevenson \& Jones, 1982), fructose-1,6bisphosphate and dihydroxyacetone phosphate (Michal \& Beutler, 1975), ATP (Jaworek \& Welsch, 1985) and lactate (Gutmann \& Wahlefeld, 1974) were performed according to the literature. Protein was estimated (Lowry et al., 1951), using bovine serum albumin as a standard and the results were calculated using the linear-transform equation of Coakley \& James (1978). Assays for glycerol kinase activity were performed by the method of Bergmeyer et al. (1985) on samples prepared by the procedure of Mohri et al. (1965).

All values are given as the mean \pm s.e.m. for the number $(n)$ of determinations indicated.

Chromatography. Sperm suspensions $(15 \mathrm{ml})$ were incubated at $34^{\circ} \mathrm{C}$ with $\left[\mathrm{U}-{ }^{14} \mathrm{C}\right] \mathrm{glycerol}(400-500 \mu \mathrm{Ci}, 2 \mathrm{mmol} / 1)$ and $\mathrm{CHOP}(1 \mathrm{mmol} / \mathrm{l})$ and terminated after 0 and $\mathrm{I} \mathrm{h}$ by addition of 2,4-dinitrophenylhydrazine reagent (method 2 of Vogel, 1957) $(1 \mathrm{ml})$ and ethyl acetate $(1 \mathrm{ml})$. Protein was removed by centrifugation $(2000 \mathrm{~g}$ for $5 \mathrm{~min})$, and the ethyl acetate was phase-dried $\left(\mathrm{Na}_{2} \mathrm{SO}_{4}\right)$ and applied as streaks to the origins of separate pre-coated thin-layer chromatography (TLC) plates of silica gel G (Merck, Darmstadt, Germany). The plates were developed in solvent A (ethy! formate:petroleum ether (b.p. $30-100^{\circ} \mathrm{C}$ ):glacial acetic acid 50:25:8 by volume). Identical incubations were terminated at 0 and $1 \mathrm{~h}$ by addition of $\mathrm{HClO}_{4}(3 \mathrm{~mol} / \mathrm{l}, 1 \mathrm{ml})$, the protein was removed by centrifugation and the supernatant solutions were neutralized and de-salted (Jones \& Chantrill, 1989). The samples were freeze-dried and the residues were dissolved in phenol-saturated water $(0.5 \mathrm{ml})$ and chromatographed on Whatman No. 1 papers in either solvent $\mathrm{B}$ ( $50 \mathrm{~g}$ phenol, $19.75 \mathrm{ml}$ water) or solvent $\mathrm{C}$ ( $n$-butanol:glacial acetic acid:water $52: 13: 35$ by volume), with authentic glyceraldehyde and dihydroxyacetone. Paper chromatograms were developed with the $p$-anisidine reagent of Putman (1957) and, with the TLC plates, scanned for radioactivity on a Berthold LB 2723 Mark 2 radiochromatogram scanner (Berthold, Wildbad, Germany).

\section{Results}

\section{Oxidation of ${ }^{14} \mathrm{C}$-labelled substrates to lactate and $\mathrm{CO}_{2}$}

More lactate accumulated in $1 \mathrm{~h}$ from glycerol than from glycerol-3-phosphate but, in the presence of CHOP, the concentration of lactate remained constant (Fig. 1). High concentrations of

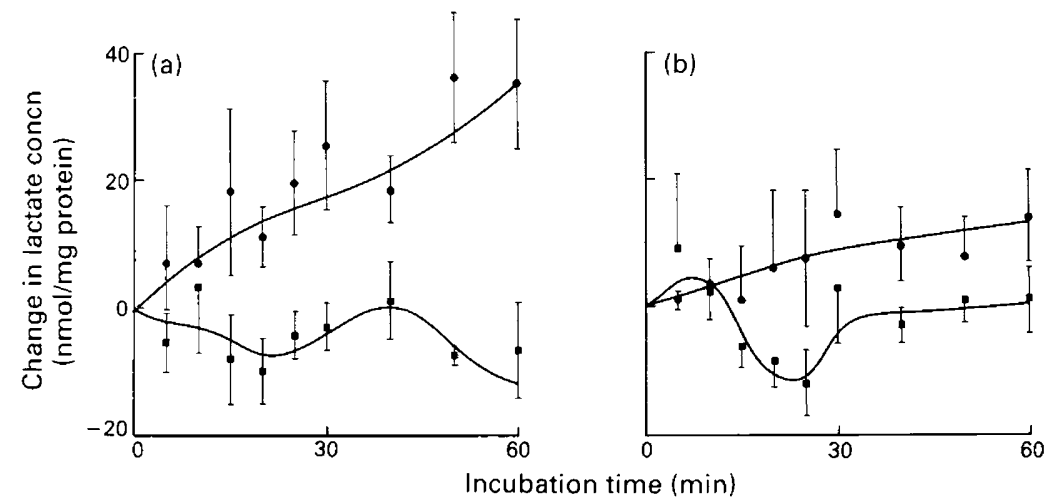

Fig. 1. Change in lactate concentration in boar spermatozoa incubated at $34^{\circ} \mathrm{C}$ with (a) $2 \mathrm{mmol}$ glycerol/1 and (b) $2 \mathrm{mmol}$ glycerol-3-phosphate/ 1 in the absence $(\boldsymbol{O})$ and presence $(\boldsymbol{\square})$ of $0.5 \mathrm{mmol} 3$-chloro-1-hydroxypropanone/l (mean \pm s.e.m., $n=4)$.

ATP were maintained for $1 \mathrm{~h}$ from both glycerol $(9 \cdot 4 \pm 1 \cdot 5)$ and glycerol-3-phosphate (8.4 $\pm 1 \cdot 4)$ (nmol/mg protein, $n=4$ ). With glycerol as the substrate, the presence of CHOP did not affect the concentration of dihydroxyacetone phosphate from a pre-incubation value of $281 \pm 60$ to $275 \pm 52$ after $1 \mathrm{~h}$, but, with glycerol-3-phosphate as the substrate, the pre-incubation value of $322 \pm 93$ increased to $1610 \pm 860(\mathrm{nmol} / \mathrm{mg}$ protein, $n=5)$. More $\mathrm{CO}_{2}$ was produced in $1 \mathrm{~h}$ from $\left[\mathrm{U}-{ }^{14} \mathrm{C}\right] \mathrm{glycerol}-3-$ phosphate than from $\left[\mathrm{U}-{ }^{14} \mathrm{C}\right] \mathrm{glycerol}$, but the presence of $\mathrm{CHOP}$ inhibited its 
production to similar extents from both substrates (Fig. 2). When $\left[1,3-{ }^{14} \mathrm{C}\right]$ glycerol and $\left[2-{ }^{14} \mathrm{C}\right]$ glycerol were offered as substrates, the production of $\mathrm{CO}_{2}$ in $1 \mathrm{~h}$ was $47.0 \pm 5 \cdot 2$ and $43.9 \pm 6.4 \mathrm{nmol} / \mathrm{mg}$ protein $(n=6)$, respectively, similar to that from $\left[\mathrm{U}-{ }^{14} \mathrm{C}\right]$ glycerol. The presence of $\mathrm{CHOP}$ inhibited the production of ${ }^{14} \mathrm{CO}_{2}$ in $1 \mathrm{~h}$ from $\left[1,3-{ }^{14} \mathrm{C}\right]$ glycerol and $\left[2-{ }^{14} \mathrm{C}\right]$ glycerol to similar extents $(20 \cdot 6 \pm 5 \cdot 3$ and $17.5 \pm 5.5 \mathrm{nmol} / \mathrm{mg}$ protein, $n=6$, respectively $)$.

\section{Determination of glycerol kinase activity}

The activity of this enzyme could not be detected in sperm sonicates $(n=5)$. Addition of authentic glycerol kinase to the reaction cuvettes gave a positive response.

\section{Dihydroxyacetone and glyceraldehyde as potential substrates}

ATP in spermatozoa incubated for $1 \mathrm{~h}$ with dihydroxyacetone or glyceraldehyde was maintained at pre-incubation concentrations (Fig. 3); the presence of $0.5 \mathrm{mmol} \mathrm{CHOP} / 1$ inhibited its production. With dihydroxyacetone, lactate accumulated from a pre-incubation value of $19 \pm 4$ to $38 \pm 17$; in the presence of CHOP, this fell to $9 \pm 4(\mathrm{nmol} / \mathrm{mg}$ protein, $n=4)$. With glyceraldehyde, lactate accumulated from a pre-incubation value of $22 \pm 2$ to $43 \pm 5$; in the presence of CHOP, this fell to $12 \pm 4(\mathrm{nmol} / \mathrm{mg}$ protein, $n=4)$. In the presence of $1 \mathrm{mmol}$ CHOP $/ 1$, dihydroxyacetone phosphate and fructose-1,6-bisphosphate accumulated after $1 \mathrm{~h}$ when dihydroxyacetone was offered as the substrate, but not when glyceraldehyde was offered (Fig. 4).

\section{Glyceraldehyde as an intermediate of glycerol metabolism}

When spermatozoa was incubated with $\left[\mathrm{U}-{ }^{14} \mathrm{C}\right]$ glycerol for 0 and $1 \mathrm{~h}$ in the presence and absence of $\mathrm{CHOP},\left[{ }^{14} \mathrm{C}\right]$ glyceraldehyde was detected after $1 \mathrm{~h}$, but only when CHOP was present, and was not detected at zero time. Analysis of incubates by TLC showed the presence of one radioactive 2,4-dinitrophenylhydrazone at $R_{\mathrm{F}} 0 \cdot 49\left(R_{\mathrm{F}}\right.$ of authentic glyceraldehyde-2,4-dinitrophenylhydrazone was 0.47 ). Paper chromatography showed the presence of one radioactive triose at $R_{\mathrm{F}}$ 0.65 and 0.50 in solvents $\mathrm{B}$ and $\mathrm{C}$, respectively. In these solvent systems, glyceraldehyde has $R_{\mathrm{F}}$ values of 0.56 and 0.52 , while those for dihydroxyacetone are 0.90 and 0.48 .

\section{Discussion}

We have previously observed that, in the presence of $0.5 \mathrm{mmol} \mathrm{CHOP} / \mathrm{l}$, incubates of boar spermatozoa are capable of synthesizing more than twice the amount of ATP when 2 mmol glycerol/1 is the substrate than when $1 \mathrm{mmol}$ fructose/l is offered (Cooney \& Jones, 1988). This led to the finding that $(S)$-3-chlorolactaldehyde, the active metabolite of both $(S)$ - $\alpha$-chlorohydrin and CHOP, was an inhibitor of triosephosphate isomerase as well as of glyceraldehyde-3-phosphate dehydrogenase (Cooney \& Jones, 1988). However, this finding did not resolve the original observation: why should the inhibition of two glycolytic enzymes not affect the metabolism of fructose and glycerol to similar extents, as the oxidation of either substrate should require both enzymes?

Glycerol was oxidized to $\mathrm{CO}_{2}$ more slowly than glycerol-3-phosphate, but the presence of $1 \mathrm{mmol} \mathrm{CHOP} / \mathrm{l}$ reduced the rate of production of $\mathrm{CO}_{2}$ by similar proportions. This, and the fact that glycerol kinase activity could not be detected, indicated that glycerol must enter the glycolytic pathway in boar spermatozoa by a route other than the sequence glycerol $\rightarrow$ glycerol-3-phosphate $\rightarrow$ dihydroxyacetone phosphate. As the effect of CHOP on the oxidation of $\left[\mathrm{U}-{ }^{14} \mathrm{C}\right],\left[1,3-{ }^{14}\right]$ and $\left[2-{ }^{14} \mathrm{C}\right]$ glycerol to ${ }^{14} \mathrm{CO}_{2}$ was similar, glycerol must enter the glycolytic pathway as a $\mathrm{C}_{3}$ metabolite which is converted to glyceraldehyde-3-phosphate. Two possible pathways for this are glycerol $\rightarrow$ glyceraldehyde $\rightarrow$ glyceraldehyde-3-phosphate and glycerol $\rightarrow$ dihydroxyacetone $\rightarrow$ dihydroxyacetone phosphate $\rightarrow$ glyceraldehyde-3-phosphate. Both intermediates, glyceraldehyde and dihydroxy- 


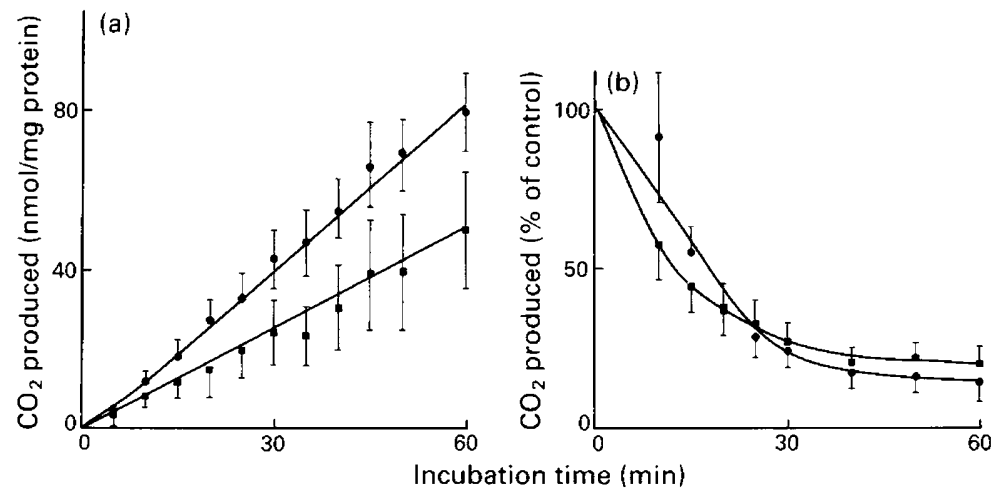

Fig. 2. Production of $\mathrm{CO}_{2}$ by boar spermatozoa incubated at $34^{\circ} \mathrm{C}$ with $2 \mathrm{mmol}$ glycerol/1 ( $\square$ ) and $2 \mathrm{mmol}$ glycerol-3-phosphate $/ \mathrm{l}(\bullet)$ in the (a) absence and (b) presence of $0.5 \mathrm{mmol}$ 3-chloro-1-hydroxypropanone/l (mean \pm s.e.m., $n=8$ ).

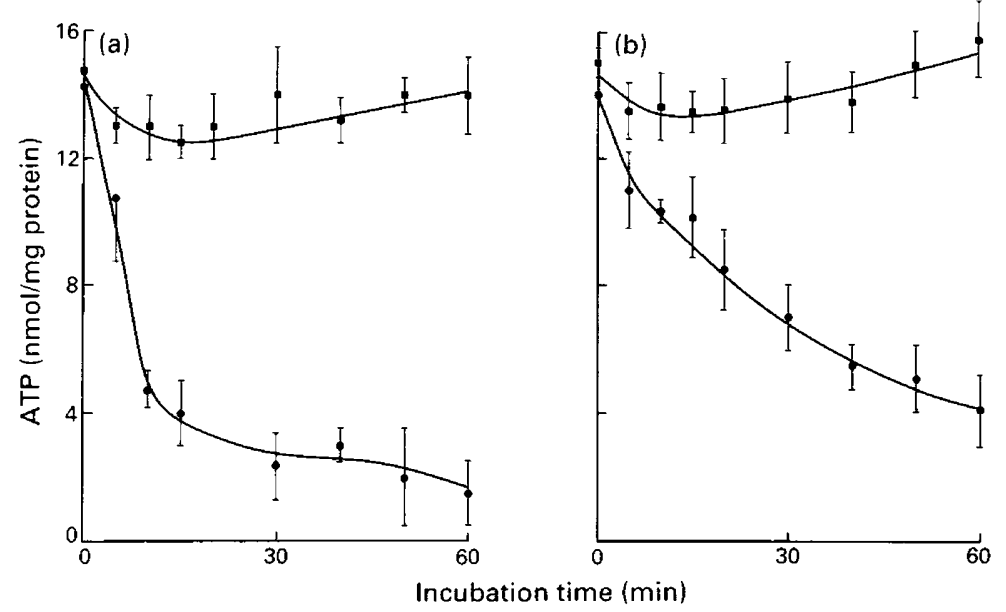

Fig. 3. Concentration of ATP in boar spermatozoa incubated at $34^{\circ} \mathrm{C}$ with (a) 2 mmol dihydroxyacetone $/ \mathbf{l}$ and (b) $2 \mathrm{mmol}$ glyceraldehyde/l in the absence ( $\boldsymbol{\square}$ ) and presence ( $)$ of $0.5 \mathrm{mmol} 3$-chloro-1-hydroxypropanone/l (mean \pm s.e.m., $n=4$ ).

acetone (which are unavailable in radiolabelled form), could be used as substrates by boar spermatozoa, as they were converted to lactate and enabled high concentrations of ATP to be maintained during the incubation period; these processes were inhibited in the presence of CHOP and did not occur in the absence of either intermediate.

When dihydroxyacetone was incubated in the presence of CHOP, dihydroxyacetone phosphate and fructose-1,6-bisphosphate accumulated, but this did not occur when glyceraldehyde was the substrate. This was similar to incubations containing glycerol-3-phosphate and glycerol as the respective substrates and suggested that glycerol is oxidized to glyceraldehyde, whereas dihydroxyacetone is phosphorylated to dihydroxyacetone phosphate. Confirmation of the involvement of glyceraldehyde as an intermediate in the metabolism of glycerol was obtained by identifying its formation and presence when glycerol was incubated in the presence of CHOP.

Although the enzyme responsible for the oxidation of glycerol to glyceraldehyde in boar spermatozoa has not been identified, evidence from investigations in other tissues suggests that it 


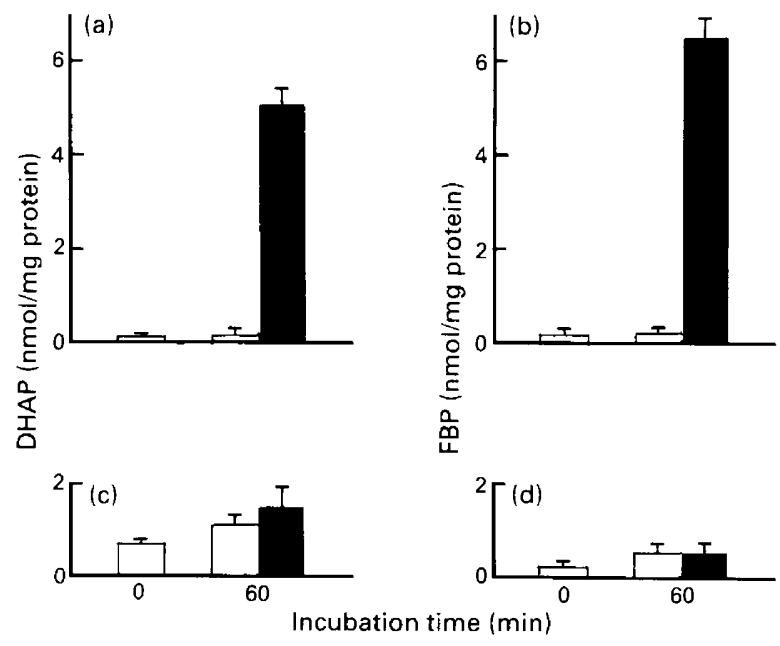

Fig. 4. Concentration of dihydroxyacetone phosphate (DHAP) and fructose-1,6-bisphosphate (FBP) in boar spermatozoa incubated at $34^{\circ} \mathrm{C}$ with (a and b) 2 mmol dihydroxyacetone/l and (c and d) $2 \mathrm{mmol}$ glyceraldehyde/l in the absence ( $\square$ ) and presence ( $\mathbf{\square})$ of $1 \mathrm{mmol} 3$-chloro-1hydroxypropanone/l (mean \pm s.e.m., $n=6$ ).

may be an $\mathrm{NADP}^{+}$-dependent dehydrogenase. Rat (Toews, 1966) and rabbit (Korman et al., 1972) skeletal muscle and human erythrocytes (Beutler \& Guinto, 1974) possess such enzymes, although kinetic studies indicate that the reaction strongly favours glycerol formation (Toews, 1967). We have noted that $(S)$ - $\alpha$-chlorohydrin is metabolized by boar spermatozoa to $(S)$-3-chlorolactaldehyde by an enzyme that is involved in the oxidation of glycerol to glyceraldehyde (Jones \& Stevenson, 1983) but any implications as to the existence of this pathway in boar spermatozoa would only be speculative. However, its presence may explain why the antiglycolytic activity of $(S)$ - $\alpha$-chlorohydrin on mature spermatozoa in vitro is species-specific (Jones, 1983).

This work was supported by a grant from the New South Wales Government Employees Assistance to Medical Research Fund. We acknowledge the assistance of the staff at F.C. Nichols Pty Ltd Abattoir, Woy Woy, NSW, in the collection of tissues.

\section{References}

Aalbers, J.G., Mann, T. \& Polge, C. (1961) Metabolism of boar semen in relation to sperm motility. $J$. Reprod. Fert. 2, 42-53.

Bergmeyer, H.U., Grassl, M. \& Waller, H.-E. (1985) Biochemical reagents for general use: enzymes. In Methods of Enzymatic Analysis, 3rd edn, Vol. 2, pp. 126.327. Ed. H. U. Bergmeyer, Verlag Chemie, Weinheim.

Beutler, E. \& Guinto, E. (1974) The reduction of glyceraldehyde by human erythrocytes. L-Hexonate dehydrogenase activity. J. clin. Invest. 53, 1258-1264.

Coakley, W.T. \& James, C.J. (1978) A simple linear transform for the Folin-Lowry protein calibration curve to $1.0 \mathrm{mg} / \mathrm{ml}$. Analyt. Biochem. 85, 90-97.

Cooney, S.J. \& Jones, A.R. (1988) Inhibitory effects of (S)3-chlorolactaldehyde on the metabolic activity of boar spermatozoa in vitro. J. Reprod. Fert. 82, 309-317.
Cooper, T.G. \& Brooks, D.E. (1981) Entry of glycerol into the rat epididymis and its utilization by epididymal spermatozoa. J. Reprod. Fert. 61, 163-169.

Gutmann, I. \& Wahlefeld, A.W. (1974) L(+)Lactate determination with lactate dehydrogenase and NAD. In Methods of Enzymatic Analysis, 2nd edn, pp. 1464-1468. Eds H. U. Bergmeyer \& K. Gawehn. Academic Press, New York.

Jaworek, D. \& Welsch, J. (1985) Adenosine 5'-triphosphate. UV-method with phosphoglycerate kinase. In Methods of Enzymatic Analysis, pp. 340-345. Ed. H. U. Bergmeyer, Verlagsgesellschaft, Weinheim.

Jones, A.R. (1983) Antifertility actions of $\alpha$-chlorohydrin in the male. Aust. J. biol. Sci. 36, 333-350.

Jones, A.R. \& Chantrill, L.A. (1989) Oxidative metabolic activity of boar spermatozoa: a system for assessing Downloaded from Bioscientifica.com at 04/26/2023 11:34:17AM 
anti-glycolytic activity of potential inhibitors in vitro. Reprod. Fert. Dev. 1, 357-367.

Jones, A.R. \& Cooney, S.J. (1987) Inhibition of triosephosphate isomerase in boar spermatozoa by (S)-3-chlorolactaldehyde. Biochem. biophys. Res. Commun. 145, 1054-1058.

Jones, A.R. \& Stevenson, D. (1983) Formation of the active antifertility metabolite of $(S)$ - $\alpha$-chlorohydrin in boar sperm. Experientia 39, 784-785.

Jones, A.R., Bubb, W.A., Murdoch, S.R. \& Stevenson, D.A. (1986) Inhibition of fructolytic enzymes in boar spermatozoa by $(S)$ - $\alpha$-chlorohydrin and 1-chloro-3hydroxypropanone. Aust. J. biol. Sci. 39, 395-406.

Kormann, A.W., Hurst, R.O. \& Flynn, T.G. (1972) Purification and properties of an $\mathrm{NADP}^{+}$-dependent glycerol dehydrogenase from rabbit skeletal muscle. Biochim. biophys. Acta 258, 40-55.

Lowry, O.H., Rosebrough, N.J., Farr, A.L. \& Randall, R.J. (1951) Protein measurement with the Folin phenol reagent. J. biol. Chem. 193, 265-275.

Mann, T. \& White, I.G. (1956) Metabolism of glycerol, sorbitol and related compounds by spermatozoa. Nature, Lond. 178, 142-143.

Mann, T. \& White, I.G. (1957) Glycerol metabolism by spermatozoa. Biochem. J. 65, 634-639.

Michal, G. \& Beutler, H.-O. (1975) D-Fructose-1,6diphosphate, dihydroxyacetone phosphate and Dglyceraldehyde-3-phosphate. In Methods of Enzymatic Analysis, vol. 3, pp. 1314-1319. Ed. H. U. Bergmeyer. Academic Press, New York.

Mohri, H. \& Masaki, J. (1967) Glycerokinase and its possible role in glycerol metabolism of bull spermatozoa. J. Reprod. Fert. 14, 179-194.

Mohri, H., Mohri, T. \& Ernster, L. (1965) Isolation and enzymic properties of the midpiece of bull spermatozoa. Exp. Cell Res. 38, 217-246.
Mohri, H., Hasegawa, S. \& Masaki, J. (1970) Seasonal change in glycerol kinase activity of goat spermatozoa. Biol. Reprod. 2, 352-355.

Murdoch, R.N. \& White, I.G. (1968) Studies of the metabolism of human spermatozoa. J. Reprod. Fert. 2, 42-53.

Putman, E.W. (1957) Paper chromatography of sugars. In Methods in Enzymology, vol. 3, pp. 62-72. Eds S. P. Colowick \& N. O. Kaplan. Academic Press, New York.

Stevenson, D. \& Jones, A.R. (1982) Inhibition of fructolysis in boar spermatozoa by the male antifertility agent $(S)$ $\alpha$-chlorohydrin. Aust. J. biol. Sci. 35, 595-605.

Stevenson, D. \& Jones, A.R. (1985) Production of (S)-3chlorolactaldehyde from $(S)$ - $\alpha$-chlorohydrin by boar spermatozoa and the inhibition of glyceraldehyde 3phosphate dehydrogenase in vitro. J. Reprod. Fert. 74, $157-165$.

Stryer, L. (1988) Biochemistry, 3rd edn, p. 472. Freeman, New York.

Toews, C.J. (1966) Evidence for the metabolism of glycerol by skeletal muscle and the presence of a muscle nicotinamide-adenine dinucleotide phosphatedependent glycerol dehydrogenase. Biochem. J. 98, 27C-29C.

Toews, C.J. (1967) The kinetics and reaction mechanism of the nicotinamide-adenine dinucleotide phosphatespecific glycerol dehydrogenase of rat skeletal muscle. Biochem. J. 105, 1067-1073.

Vogel, A.I. (1957) Practical Organic Chemistry, p. 1061. Longmans, London.

White, I.G. (1957) Metabolism of glycerol and similar compounds by bull spermatozoa. Amer. J. Physiol. $189,307-310$.

Received 29 October 1990 